\section{LA QUÍMICA ESPAÑOLA EN EL AÑO INTERNACIONAL DE LA QUÍMICA}

\author{
Luis A. Oro
}

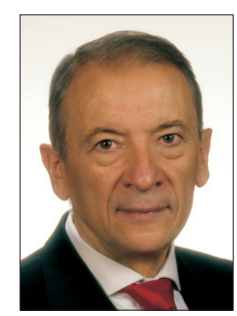

El año 2011 es un año singular para la Química, al haber sido declarado por la UNESCO como Año Internacional de la Química. La iniciativa surgió en la Asamblea de la IUPAC celebrada en Turín, en agosto de 2007. Al año siguiente el comité ejecutivo de la UNESCO recomendó elevar la propuesta a la Asamblea de las Naciones Unidas, quien finalmente, en diciembre de 2008, aprobó formalmente la declaración del año 2011 como Año Internacional de la Química. A lo largo de este año 2011, tras una inauguración formal en enero en la sede de la UNESCO en París, se celebran en todo el mundo una serie de actos conmemorativos, entre los que destaca el Congreso IUPAC en San Juan de Puerto Rico, que se celebrará en agosto con la participación de siete Premios Nobel de Química. La clausura formal se realizará en diciembre en Bruselas.

Bajo el lema "Chemistry: our life, our future" las metas de esta conmemoración son: incrementar la apreciación pública de la Química como herramienta fundamental para satisfacer las necesidad de la sociedad, promover el interés por la química entre los jóvenes, y generar entusiasmo por el futuro creativo de la química.

El año 2011 coincide con el centenario del Premio Nobel de Química otorgado a Marie Curie y de la fundación de la Asociación Internacional de Sociedades Químicas. La conmemoración enfatiza la contribución de la química como ciencia creativa esencial para mejorar la sostenibilidad de nuestros modos de vida y para resolver los problemas globales y esenciales de la Humanidad.

Conviene recordar que la Química floreció en Europa hace unos doscientos cincuenta años, y ha sido fundamental en la mejora de nuestra calidad de vida. Se considera a Antoine Lavoisier el padre de la química moderna y fue el fundador, en 1789 en París, de la primera revista del mundo dedicada exclusivamente a la química, Annales de Chimie. Resulta destacable señalar que dos años más tarde nacía en España la revista Anales de Química de Segovia, dirigida por Luis Proust, pero debido a las desgraciadas turbulencias en España al inicio del siglo XIX no fue posible su continuidad, si bien nuestra centenaria Real Sociedad Española de Química ha mantenido el nombre de Anales de Química para su revista social.

La Química es una ciencia central que por su propia naturaleza ocupa un lugar destacado entre todas las disciplinas científicas, con las que está estrechamente relacionada. Forma la base de todas las ciencias moleculares como la Biología, Farmacia, Ciencia de Materiales, etc. Su ámbito es universal. Con más de cien elementos conocidos y técnicas de sintesis química que evolucionan constantemente, las oportunidades para diseñar y hacer nuevas moléculas son casi infinitas. Por otra parte, la Química es una ciencia con un brillante futuro. No hay que olvidar que esta ciencia ha proporcionado importantes aportaciones y soluciones innovadoras en el pasado y va a seguir haciéndolo en el futuro en aspectos tan relevantes como un mejor entendimiento de la química de la vida, o la creación de moléculas y materiales con propiedades y aplicaciones insospechadas.

Hace unos años, a finales del siglo pasado, el entonces editor de Nature, John Maddox, publicó un libro titulado "Lo que nos queda por descubrir", del que parecía desprenderse la idea de que el tiempo de la química como ciencia "estrella" había pasado. En mi opinión los avances de la investigación en las últimas décadas ponen de manifiesto que dicha tesis no es correcta, ya que la química es también una ciencia transversal que alimenta a campos tan diversos como la ciencia de los materiales, la biomedicina o la biología molecular, conexiones que son el vivero de 
los descubrimientos y tecnologías del futuro. Sin duda, los grandes retos de un mundo con población y demandas crecientes necesitan de la contribución de la química.

Tal vez los químicos no hemos sido capaces de hacer llegar a la sociedad y a los medios la contribución fundamental de la química, y algunos descubrimientos importantes basados en la investigación química aparecen catalogados como avances de otras disciplinas. El prestigioso químico orgánico Georges Whitesides señala: "The nature of the cell is an entirely molecular problem. It has nothing to do with biology." Lo que sí es cierto es que no resulta tan fácil plantear desde la química, preguntas atractivas para nuestra sociedad, como hacen nuestros colegas de física o biología, al preguntar, en público, ¿cuál es el origen del universo, o cuál es el origen de la vida?

En mi opinión uno de los retos más importantes de la Química es contribuir a sentar las bases de un desarrollo sostenible del planeta Tierra evitando un consumo insostenible de los recursos. La energía, el agua, los alimentos y el medio ambiente son los cuatro retos más importantes de nuestro mundo, y la química es una ciencia fundamental para proponer posibles opciones para su solución, y resulta ser totalmente necesaria para proporcionar las bases que permitan realizar un balance inteligente, en todo momento, del binomio riesgo/beneficio. Sin duda, en este siglo XXI, el desarrollo sostenible de nuestro planeta necesita de la Química y su capacidad permanente de aportar soluciones a las crecientes y cada vez más complejas demandas de nuestra sociedad. Así, por ejemplo, si nos referimos al reto universal de la energía, acaso debiéramos transmitir que el almacenamiento y conversión de energía pasa necesariamente por la energía asociada a enlaces químicos.

\section{LA INVESTIGACIÓN OUÍMICA ESPAÑOLA: LUCES Y SOMBRAS}

La investigación química en España ha evolucionado en las últimas décadas de un modo muy positivo, como ha sido la tónica general de la ciencia española. La bases de datos de ISI Web of Knowledge nos permite observar algunos parámetros de crecimiento. Así, la Tabla 1 recoge la posición relativa de nuestro país en el concierto internacional, en lo referente a publicaciones científicas y citas recibidas por el conjunto de publicaciones españolas en todas las áreas, agrupadas en períodos de diez años.

TABLA 1

\begin{tabular}{|l|c|c|c|c|}
\hline \multicolumn{1}{|c|}{ Posición de España en el mundo } & $\mathbf{1 9 9 2 - 2 0 0 2}$ & $\mathbf{1 9 9 5 - 2 0 0 5}$ & $\mathbf{1 9 9 7 - 2 0 0 7}$ & $\mathbf{2 0 0 0 - 2 0 1 0}$ \\
\hline Ranking por artículos & 11 & 10 & 10 & 9 \\
\hline Ranking por citas & 12 & 11 & 11 & 11 \\
\hline Citas por artículo & 6,27 & 7,52 & 8,32 & 10,18 \\
\hline
\end{tabular}

Dicha tabla muestra que en los últimos años hemos avanzado dos posiciones en publicaciones, aunque solo una en citas, a pesar del crecimiento continuado en las citas recibidas por artículo. Una publicación relativamente reciente, sobre la base de datos "ISIHighlyCited" relacionaba los veinte países con mayor número de "highly cited researchers" por millón de habitantes, siendo los primeros de la lista, Estados Unidos (16,82), Suiza $(16,28)$ e Israel $(12,49)$, mientras que las tres últimas posiciones, entre los veinte, correspondían a Singapur
$(1,66)$, Austria $(1,59)$ e Italia $(1,28)$. España, ausente en este listado tendría un valor del orden de 0,5, habida cuenta de la presencia de 25 "highly cited researchers" españoles.

Cuando se analiza la competitividad científica española en las diversas áreas aparecen notorias diferencias. La Tabla 2 muestra la posición relativa española en el período 20002010, en lo referente a publicaciones científicas y citas recibidas, ordenadas por este último concepto. 


\begin{tabular}{|l|c|c|}
\hline & Ranking por citas & 9 \\
\hline Química & 7 & 10 \\
\hline Matemáticas & 8 & 6 \\
\hline Microbiología & 8 & 11 \\
\hline Física & 9 & 11 \\
\hline Ciencia de Materiales & 10 & 12 \\
\hline Ingeniería & 11 & 9 \\
\hline Biología Molecular y Genética & 11 & 13 \\
\hline Inmunología & 12 & 11 \\
\hline Medicina Clínica & 12 & 11 \\
\hline Farmacología y Toxicología & 12 & 9 \\
\hline Biología y Bioquímica & 12 & 12 \\
\hline Ciencias Geológicas & 13 & 8 \\
\hline Ciencias Sociales & 14 & \\
\hline
\end{tabular}

Dicha tabla pone de manifiesto la competitividad interáreas de la química, ya que es la única área científica española que alcanza el lugar séptimo en lo referente al número de citas recibidas, mientras que se encuentra en el lugar noveno en lo relativo al número de publicaciones. Resulta destacable que las áreas que mejoran en dos posiciones su posición entre citas y publicaciones, son precisamente las áreas clásicas de Ciencias (Química, 7, 9: Matemáticas, 8, 10; y Física, 9, 11). Otras áreas que mejoran una posición son Ciencia de Materiales $(10,11)$, Ingeniería $(11,12)$ e Inmunología $(12,13)$. Parece desprenderse de los datos mencionados que la investigación química española es razonablemente competitiva, pero ise plasma ello en una financiación acorde con su nivel competitivo? La respuesta, tras un simple análisis de la financiación del Plan Nacional de $I+D+i$, comparada con otras áreas, no puede ser afirmativa. El porcentaje de proyectos aprobados y su financiación es inferior a otras áreas aparentemente no tan competitivas. Esperemos que esta tendencia sea corregida adecuadamente en un futuro próximo. No obstante, en algunos sectores de la investigación científica, incluida la química, hay una cierta preocupación ante los compromisos de nuestro sistema de financiación de la investigación, con el mapa establecido de instalaciones científicas, que un momento de posibles dificultades económicas pueden absorber en su mantenimiento recursos preciosos y no totalmente justificados.

¿Son suficientes la inversiones españolas en investigación? Un análisis comparado del contexto internacional pone de manifiesto que España realiza una inversión pública razonable, pero sin embargo el sector privado, a pesar de un marco legislativo muy favorable, realiza una inversión insuficiente. En esta línea, y referidos a un trienio reciente, mientras dos tercios de las empresas alemanas introducen algún tipo de innovación, solo un tercio de las empresas españolas lo han hecho, lo que nos sitúa en las últimas posiciones de la zona euro. Por otra parte, sólo el 5\% de las empresas innovadoras colaboran con alguna institución universitaria.

Desde un punto de vista comparado la investigación química española está bien pero podría estar mejor, o al menos aspirar a ello. Nuestra investigación se publica, en general, en revistas de impacto promedio razonable, pero tal vez sea conveniente reflexionar si tiene sentido 
invertir nuestro tiempo y fondos públicos en algunas temáticas demasiado continuistas, en lugar de plantearnos investigaciones de mayor riesgo. Creo que este es uno de los retos que los investigadores en química españoles debemos afrontar. Nuestra comunidad ha alcanzado un buen nivel internacional, y es el momento de dar un salto cualitativo, con objetivos más ambiciosos, que nos sitúen en la frontera del conocimiento. Nuestros investigadores químicos tienen, en general, la formación y ambición necesaria para acometer este reto. Este Año Internacional de la Química puede ser una buena ocasión para afrontar ese desafío. 